\title{
La ciencia, también de su lado
}

\section{María González Lacabex ${ }^{1}$}

"La cuestión no es ¿Pueden razonar? ni ¿Pueden hablar? sino ¿Pueden sentir?”2. El célebre enunciado del filósofo inglés Jeremy Bentham (1748-1832) constituye la síntesis de uno de los grandes pilares sobre los que descansa el argumentario actual en favor de la defensa de los animales: su capacidad de sentir, de donde nace el deber ético de protegerles frente al dolor, la angustia, el sufrimiento. $Y$ es precisamente esa capacidad de sentir el fundamento sobre el cual se ha ido configurando en la Unión Europea todo un entramado normativo dirigido a garantizar el bienestar y la protección de los animales en los diversos ámbitos en los que son utilizados por los seres humanos. El papel de la ciencia en esta evolución ha sido y sigue siendo determinante, de forma que los nuevos conocimientos científicos que demuestran la capacidad de sentir por parte de animales no humanos han impulsado el desarrollo de estas normas, ampliando tanto su alcance como sus estándares de protección. Así, la consagración del bienestar animal como valor comunitario, queda fundamentada en la consideración de los animales como "seres sintientes", gracias a la constatación científica de dicha condición.

\footnotetext{
${ }^{1}$ María González Lacabex, Abogada. Máster en Derecho del Medio Ambiente. Especialista Universitaria en Desarrollo Sostenible y Agenda 21 Local. Postgrado Animales, Derecho y Sociedad (UAB, 2011). Promotora de ANIMALEX, despacho dedicado exclusivamente a Derecho Animal.

${ }^{2}$ Sobre Jeremy Bentham, vid. O. Caudevilla Parellada, Jeremy Bentham, a pioneer. dA web Center Enero 2013.

${ }^{3}$ Artículo 13 del Tratado de Funcionamiento de la Unión Europea (Tratado de Lisboa): "(...) the Union and the Member States shall, since animals are sentient beings, pay full regard to the welfare requirements of animals (...)".
} 
La Directiva 2010/63, relativa a la protección de los animales utilizados para fines científicos ${ }^{4}$, constituye un buen ejemplo de lo anterior. Así lo expresaba en sus considerandos:

"(6) Hay nuevos conocimientos científicos sobre los factores que influyen en el bienestar de los animales y su capacidad de sentir y expresar dolor, sufrimiento, angustia y daño duradero. Resulta, pues, necesario, aumentar el bienestar de los animales utilizados en procedimientos científicos elevando los niveles mínimos de protección de esos animales de acuerdo con los avances científicos más recientes". "(10) (...) La presente Directiva debe revisarse con regularidad a la luz de la evolución de la ciencia y de las medidas de protección de los animales".

Los resultados de las investigaciones realizadas y el desarrollo del conocimiento de que disponemos sobre la capacidad - objetiva y verificable - de seres no humanos de padecer sufrimiento físico y psicológico está permitiendo no sólo aumentar los niveles mínimos de protección de los animales sino también extender dicho amparo a nuevas especies antes no contempladas. En este sentido, la citada Directiva dio un importante paso adelante, al incorporar en su ámbito de aplicación (que inicialmente sólo comprendía a los animales vertebrados), por un lado, a los cefalópodos (pulpos, calamares, sepias y nautilos), "ya que existen pruebas científicas de su capacidad de experimentar dolor, sufrimiento, angustia y daño duradero" $\mathrm{y}$, por otro, a los fetos de los mamíferos, al haberse probado científicamente que "esas formas, en el último tercio del período de su desarrollo, tienen un riesgo mayor de experimentar dolor, sufrimiento y angustia, lo cual puede afectar negativamente también a su desarrollo posterior", y que "la experimentación en fetos y formas embrionarias en una fase de desarrollo poco avanzada puede provocar dolor, sufrimiento, angustia y daño duradero, si esas formas en desarrollo van a vivir más allá de los dos primeros tercios de su desarrollo".

Tras su aprobación en el año 2010 esta Directiva vuelve a ser de actualidad, una vez finalizado el plazo de que disponían los Estados miembros para incorporar sus disposiciones a los respectivos ordenamientos jurídicos internos. Con algo de retraso, el Estado español traspone esta nueva legislación a través de una modificación de la Ley 32/2007, para el cuidado de los animales en su explotación, transporte,

\footnotetext{
4 Directiva 2010/63/UE del Parlamento Europeo y del Consejo, de 22 de septiembre, relativa a la protección de los animales utilizados para fines científicos (DOUE L 276, 20-10-2010). Corrección de errores (DOUE L 163, 22-06-2012).
} 
experimentación y sacrificio $^{5}$, y de la aprobación del Real Decreto 53/2013, para la protección de los animales utilizados en experimentación y otros fines científicos, incluyendo la docencia ${ }^{6}$.

En aplicación de la Directiva europea, este Real Decreto viene a establecer en España un nuevo régimen de protección para los animales que son utilizados con fines científicos o docentes, a través de una serie de normas que inciden en las diversas fases y aspectos de la vida de estos seres: su origen, cría, identificación y registro, transporte, alojamiento, cuidados y utilización, hasta su eutanasia, realojo o reintegración en un hábitat adecuado. Todos los proyectos y procedimientos científicos o docentes que se vayan a llevar a cabo con animales van a tener que ser evaluados y autorizados conforme a estas nuevas normas, que están basadas en el principio de las tres erres ${ }^{7}$ : reducción, reemplazo y refinamiento. Es decir: que el número de animales utilizados se reduzca al mínimo, evitando toda duplicación inútil de procedimientos; que se apliquen en lo posible métodos alternativos; y que los animales reciban los cuidados adecuados, sin causarles innecesariamente dolor, sufrimiento, angustia o daño duradero.

De acuerdo con la nueva normativa, los centros dedicados a la cría, suministro y utilización de estos animales deberán estar autorizados y debidamente registrados, además de cumplir una serie de obligaciones que no se limitan a la adecuación de las instalaciones (dimensiones, condiciones ambientales, sistemas de emergencia, enriquecimiento ambiental de espacios, requerimientos para cada especie concreta de animal, etc.), sino que se concretan también en la designación de responsables (especialista en bienestar animal, veterinario, aplicadores de la normativa in situ) y en la capacitación del personal de acuerdo a una formación modular con unos contenidos mínimos y autorizada como tal por la autoridad competente. Asimismo, estos centros deberán incorporar una nueva figura, denominada Órgano Encargado del Bienestar de los Animales (en el caso de criadores y suministradores) o Comité de Ética de Experimentación Animal (en el caso de usuarios). En cada centro, este órgano desempeñará, entre otras, las siguientes funciones: asesorar al personal para el cumplimiento de esta normativa, mantenerle informado sobre los avances técnicos y

\footnotetext{
${ }^{5}$ En el momento de la publicación de este artículo, el proyecto de ley de modificación de la Ley 32/2007, de 7 de noviembre, para el cuidado de los animales, en su explotación, transporte, experimentación y sacrificio, se encuentra en fase de enmiendas.

${ }^{6}$ Real Decreto 53/2013, de 1 de febrero, por el que se establecen las normas básicas aplicables para la protección de los animales utilizados en experimentación y otros fines científicos, incluyendo la docencia BOE no 34, 08-02-2013.

${ }^{7}$ Principio formulado por los científicos británicos W. Russel y R. Burch en su obra: "The Principle of Humane Experimental Technique" (1959).
} 
científicos aplicables según el principio de las tres erres, establecer los mecanismos de seguimiento y control de la información que se genere en el centro sobre esta materia $y$, en el caso del comité ético, elaborar un informe que acompañará necesariamente a la solicitud de autorización de cualquier proyecto en el que se pretenda usar animales.

En cuanto al tipo de animales que pueden ser utilizados con fines científicos o docentes, la nueva normativa establece una serie de reglas generales, como que no pueden utilizarse animales directamente capturados en la naturaleza (determinadas especies han de proceder de animales criados con estos fines), ni que pertenezcan a especies amenazadas, ni animales asilvestrados o vagabundos de especies domésticas. Sin embargo, la realidad es que, de alguna manera, la norma mantiene siempre la puerta abierta a la excepción, para determinados supuestos y con la correspondiente autorización previa. Incluso en aquellas disposiciones más restrictivas, las relativas al uso de primates no humanos, se siguen admitiendo salvedades, de modo que, salvo en el caso de gorilas, chimpancés, bonobos y orangutanes, la utilización de otros primates puede llegar a estar permitida si se ha justificado científicamente que no pueden conseguirse los objetivos del procedimiento con otro tipo de animales, y dichos objetivos están relacionados con intereses como el tratamiento de enfermedades discapacitantes o peligrosas para la vida humana, o la conservación de especies.

En realidad, no podemos olvidar que, ante todo, la Directiva europea parte de la consideración de que la utilización de animales vivos en actividades científicas y educativas sigue siendo necesaria para proteger la salud humana, los animales y el medio ambiente. De acuerdo con ello, la protección de los animales utilizados con tal fin, por muy elevada que sea, permanecerá supeditada a la existencia de intereses considerados superiores (los que en cada momento decidan los seres humanos). En este sentido, se ha criticado a esta normativa que, aunque en algún momento apunte a ello ${ }^{8}$, en realidad no aborda el problema ético de fondo: la superioridad moral atribuida al ser humano, sobre la que descansa la justificación última de la utilización de animales, en sacrificio de su propio bienestar e intereses ${ }^{9}$.

Pues bien, es cierto $-y$, por supuesto, susceptible de crítica - que la normativa sobre experimentación con animales asume el sacrificio de los intereses de éstos como un mal menor sujeto a intereses colectivos supuestamente merecedores de mayor protección. Pero también que a través de esta legislación los Estados miembros de la

\footnotetext{
8 “(12) Los animales tienen un valor intrínseco que tiene que respetarse. Además, el público se plantea consideraciones de indole ética en relación con la utilización de animales en los procedimientos (...)”. Directiva 2010/63/UE.

${ }^{9}$ Vid. F. LEYTON, Problemas bioéticos de la experimentación con animales no humanos. dA web Center, Septiembre 2010.
} 
Unión Europea realizan una importantísima declaración, que no debe pasarse por alto: Como objetivo último, lo deseable sería sustituir los procedimientos científicos con animales vivos por otros métodos que no los usen, es decir, su PLENO REEMPLAZO, tan pronto como sea científicamente posible hacerlo. Por ello, al tiempo que se regulan las condiciones de protección que deben recibir los animales que sigue siendo necesario utilizar, se propone facilitar y fomentar el avance de enfoques alternativos, por los cuales habrá que optar tan pronto como sea posible. Una pauta que - importante precisión - no dejará de aplicarse "aunque se haya conseguido la eliminación del dolor, sufrimiento, angustia o daño duradero mediante el empleo satisfactorio de analgesia, anestesia u otros métodos"10.

La relevancia de esta declaración es seguramente mayor de lo que a primera vista pueda parecer. $Y$ es que a través de ella se está reconociendo expresamente que siempre que existan alternativas al empleo de animales para la consecución de fines de interés humano, dicha utilización deberá quedar descartada. No importa que hayamos conseguido que el animal no sufra (con unos determinados cuidados o gracias a unas sustancias específicas): la cuestión es que si existe un método alternativo para lograr el mismo fin, utilizar animales para ello deja de tener sentido. Si esto es así en el ámbito de la experimentación científica, en el que el uso de animales está sujeto en teoría a supuestos intereses superiores (como los relacionados con la salud humana o la conservación del medio ambiente), ¿cuánto más lo será en otros ámbitos en los que los animales también están a nuestro servicio sin intervenir intereses tan "elevados"? Es decir, en la medida en que existen otras opciones para alimentarnos adecuadamente, $u$ otras formas de ocio y entretenimiento, por ejemplo, ¿deberíamos seguir utilizando animales para estos fines también? El debate está - o mejor dicho, sigue - abierto. Pero con esta normativa la Unión Europea ha apuntado ya en una dirección.

Comenzamos el año 2013 con el reto de dar efectivo cumplimiento en España a la nueva normativa europea sobre experimentación con animales. Las dificultades de la puesta en práctica de sus disposiciones se irán revelando con el tiempo, y en tal medida podrán ir siendo evaluadas. Pero lo cierto es que con una declaración como la explicada esta legislación ya ha dado sin duda un valioso paso adelante en el camino hacia una efectiva protección de los animales. Un camino de no retorno, por el que a veces se tiene la sensación de avanzar de forma lenta, pero en el que, mantengamos siempre la esperanza, SE AVANZA. Y un camino en el que la ciencia, como ya ha demostrado, puede estar también de su lado.

\footnotetext{
${ }^{10}$ Artículo 2.3 del Real Decreto 53/2013.
} 